\title{
Los fosfatos del Sahara Occidental y los principales productores mundiales de roca fosfática: política versus estrategia empresarial, 1969-1975'
}

\author{
Phosphate of Western Sahara \\ and the world's major phosphate \\ rock producers: Politics versus \\ business strategy, 1969-1975
}

\section{JESÚS MARÍA MARTÍNEZ MILÁN*}

Resumen: Entre finales de la década de 1960 y principios de la de 1970, el mercado mundial de fosfatos atravesó por un periodo caracterizado por la caída de la demanda y la guerra de precios entre los principales productores. En esos momentos, un nuevo actor, el fosfato sahariano, hacía acto de presencia en el mercado mundial. En este artículo analizo las diferentes estrategias puestas en marcha por los principales productores para controlar el fosfato sahariano. Sostengo que España se alió con Marruecos con el fin de compartir el mercado con su mayor competidor. Sin embargo, esta estrategia quedó desvirtuada desde el preciso momento en que Madrid dio prioridad a los intereses de la industria de fertilizantes española sobre

Recepción: 2 de marzo de 2018. / Aceptación: 19 de julio de 2018.

* Universidad de Las Palmas de Gran Canaria, jesus.martinez@ulpgc.es

${ }^{1}$ Este trabajo se ha realizado en el marco del proyecto de investigación del Ministerio de Economía y Competitividad del Gobierno de España HAR 2014-56428C3-3-P. 
los de Fosfatos de Bu Craa, S.A. (Fosbucraa). Todo ello al comienzo de una nueva coyuntura marcada por la salida de España del Sahara y la caída de la cotización internacional del fosfato.

Palabras clave: fosfato; Sahara Occidental; minería; Marruecos; Estados Unidos.

Abstract: Between the end of the 1960s and the beginning of the 1970s, the world's phosphate market went through a period characterized by a fall in demand and a price war between the major producers. At that time, Saharan phosphate burst onto the world market. In this paper, I intend to analyze the strategies used by the major producers to control Saharan phosphate. I argue that Spain allied with Morocco in order to share the market with its biggest competitor. However, this strategy began to fail as soon as Madrid prioritized the interests of the Spanish fertilizer industry over those of Fosfatos de Bu Craa, S.A. (Fosbucraa). All this took place at the beginning of a new era marked by the withdrawal of Spain from Sahara and a fall in the international price of phosphate.

Keywords: phosphate; Western Sahara; mining; Morocco; United States.

\section{Introducción}

A diferencia de lo ocurrido en la zona norte del Protectorado español en Marruecos, donde el negocio minero estuvo en manos de la oligarquía financiera española, cuyo único objetivo fue recoger beneficios y evitar, en lo posible, realizar inversiones tanto en el mantenimiento y la renovación de los medios de producción como en la propia región (Morales Lezcano, 1976; Madariaga, 1999; Díaz Morlán, 2015), en el Sahara Occidental fue el Estado español el que puso en marcha, en 1962, la Empresa Nacional Minera del Sahara, S.A. (Enminsa) con el fin de encontrar yacimientos de fosfato comercialmente explotables en una zona, la parte septentrional de la colonia, que se venía investigando desde 1947. Dos años después (1964) no sólo se había descubierto y cubicado uno de los criaderos de fosfato más importantes del mundo en cuanto a calidad y cantidad se 
refiere, $\mathrm{Bu}$ Craa, sino que se habían proyectado las obras necesarias para su explotación.

Las grandes inversiones necesarias y los gastos desembolsados dieron paso a un déficit crónico en las cuentas de la sociedad a partir de 1965, que el gobierno español intentó atajar en los años siguientes con la búsqueda de socios norteamericanos que facilitaran la financiación. Entre 1966 y 1968, y después de un periodo de selección, Madrid entabló conversaciones con la International Mineral \& Chemical Co. (IMC). Decidido como estaba a permanecer a toda costa en el Sahara, el fracaso de las conversaciones llevó al gobierno español a financiar por su cuenta las inversiones necesarias. Para ello cambió el nombre de la sociedad a Fosfatos de Bu Craa, S.A. (Fosbucraa), incrementó su capital social hasta 5000 millones de pesetas y nombró un nuevo consejo de administración.

La aparición de Fosbucraa en el panorama mundial de los fosfatos atrajo el interés de los principales productores mundiales de roca fosfática, ya que suponía la entrada de un nuevo competidor que aportaría más fosfato de alta calidad en un periodo coyuntural, 1966 a 1971, marcado por el estancamiento de la demanda y la caída del precio mundial. Si a ello añadimos que el yacimiento de $\mathrm{Bu}$ Craa se encontraba en un territorio cuya descolonización reclamaba la ONU y que era motivo de las reivindicaciones de Marruecos, tendremos además un plus político que convirtió los fosfatos del Sahara Occidental en un objeto de deseo.

La documentación utilizada es la de la empresa Fosbucraa que se encuentra depositada en el Archivo de la Sociedad Estatal de Participaciones Industriales (ASEPI), el cual conserva los fondos del antiguo Instituto Nacional de Industria en Madrid, y la documentación diplomática de la embajada francesa en Rabat, ubicada en el Centro de Archivos Diplomáticos de Nantes. Lamentablemente, no hemos podido acceder a la que se encuentra en el Archivo General de la Administración Pública, en Alcalá de Henares, ya que la Ley de Secretos Oficiales impide, por ahora, su libre acceso.

El artículo está estructurado en cuatro apartados. En el primero se realiza un sucinto estudio de la situación del mercado mundial de fosfatos naturales en los años sesenta. En el segun- 
do se analiza el papel de las industrias de fertilizantes francesas, que figuraban entre las mayores consumidoras mundiales, en un intento de tejer una alianza entre Marruecos, España y las sociedades de fosfato de Senegal y Togo, en las que tenían una presencia accionaria mayoritaria. Para concluir, en los dos últimos apartados se abordan los intentos de dos de las mayores empresas de fosfatos, IMC y la marroquí Office Chérifien des Phosphates (OCP), por alcanzar acuerdos con Fosbucraa, y cómo los intereses de ambas partes en el mercado mundial y europeo, así como el juego político de Rabat, propiciaron, con el beneplácito español, un cártel hispano-marroquí que tuvo un corto recorrido en el tiempo.

\section{El mercado mundial de fosfatos naturales en los años sesenta}

A finales de los años sesenta, el mercado mundial de fosfatos se encontraba inmerso en una guerra de precios entre los dos mayores exportadores de fosfato: Marruecos y Florida (Estados Unidos), como consecuencia de una situación de exceso de oferta que se había generado a raíz de la caída de la demanda mundial de fertilizantes. En esos momentos, las dos terceras partes de las necesidades de fosfato de Europa y Asia eran cubiertas por ambos países, mientras que el mercado americano era abastecido casi en su totalidad por los exportadores de Florida. Como se observa en la figura 1, las exportaciones de mineral de roca de fosfato marroquí crecieron en el primer lustro de los años sesenta, hasta alcanzar el máximo en 1964 con una subida de $18 \%$ respecto al año anterior. Este aumento fue posible gracias al incremento del precio del mineral de más alta ley $(80 \% \mathrm{TCL})^{2}$ y al fuerte crecimiento del consumo interno de fosfato de Estados Unidos, que impidió a los empresarios norteamericanos disponer de mayores cantidades para su exportación al mercado europeo. A partir de ese año, la situación, que era sumamente favorable al reino alauita, cambió.

${ }^{2}$ La calidad del fosfato se define por su contenido de fósforo, que se expresa en porcentajes de fosfato tricálcico (TCL). 
FiguRa 1. Evolución de las exportaciones de fosfato de Marruecos y Florida, 1960-1970 (miles de Tm).

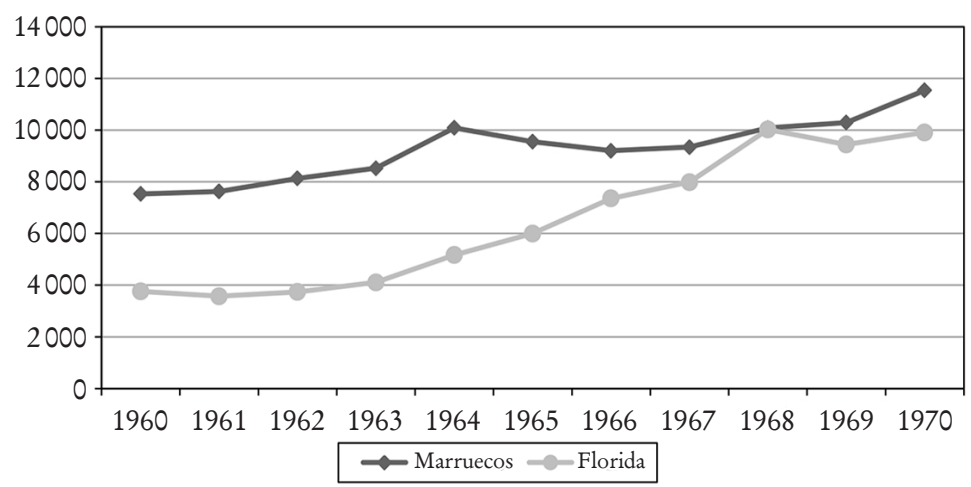

Fuente: Bureau of Mines, s.a.; Resumen Anual de Trabajos, 1968, p. 17.

Las razones de este cambio estuvieron en la mala gestión de la Office Chérifien des Phosphates ${ }^{3}$ (OCP), en el estancamiento de la demanda internacional de fertilizantes, en la política de bajos precios practicada por los productores de Florida en el mercado de Europa occidental y, por último, en el anuncio de la puesta en explotación del yacimiento de Bu Craa (mapa 1) (Oualalou, 1975; Martínez, 2017a).

La política de precios fue la que permitió a las empresas estadounidenses recuperar algo de presencia en el mercado de Europa occidental en el segundo lustro de los años sesenta, y alcanzaron el mismo nivel de exportaciones que Marruecos en 1968. Esta situación obligó a los empresarios de Florida a explotar yacimientos de fosfato de baja ley (inferior a 75\% TCL) con costos de producción elevados, debido al agotamiento que empezaban a experimentar los depósitos de ley media y a la necesidad de mantener un nivel adecuado en los stocks de fosfato de alta ley para satisfacer la demanda europea (Situación y perspectivas..., 1969, pp. 39-43). Esta situación no podía

${ }^{3}$ Creada por decreto (dahír) del 7 de agosto de 1920 para ejercer el monopolio de los fosfatos en la zona del protectorado francés en Marruecos, la OCP fue nacionalizada tras la independencia del reino alauita. 
MAPA 1. Yacimiento de fosfato de Bu Craa

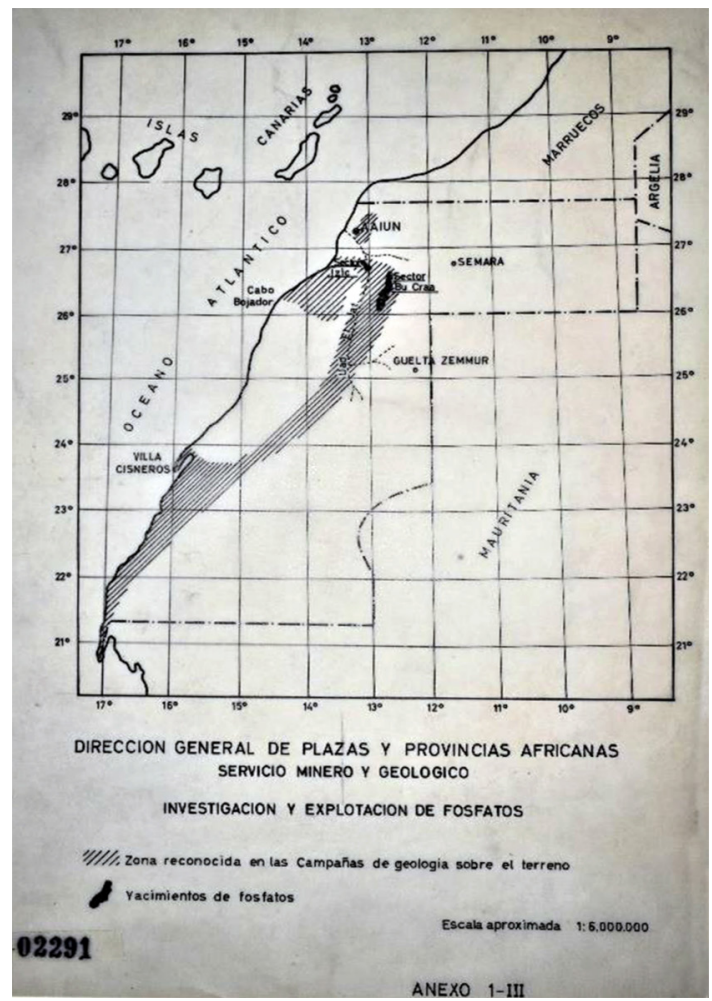

Fuente: Yacimiento de fosfato de Bu Craa.

mantenerse por mucho tiempo, ya que el precio del transporte era determinante en el precio final, lo que presagiaba una "disminución de las ventas del fosfato de Florida” en Europa, en favor del fosfato del norte de África.

A finales de 1969, las estimaciones realizadas por los directivos de la empresa española Fosbucraa sobre los precios del fosfato de calidad inferior y media (65-75\% TCL), preveían una caída continuada hasta 1975, como consecuencia del exceso de capacidad de producción sobre la demanda prevista. No ocurría lo mismo, en cambio, con el mineral de alta calidad 
( $80 \%$ TCL), debido a su creciente demanda y su escasa oferta (Situación y perspectivas..., 1969, pp. 27-28; Resumen anual de trabajos, 1970, pp. 74-75).

En una coyuntura marcada por la guerra de precios entre los principales productores de roca fosfática, aparecía un nuevo oferente, Fosbucraa, con capacidad para extraer y exportar fosfato en cantidades importantes, a precios competitivos y con una buena situación geográfica respecto a los grandes países exportadores de fosfato, si se tiene en cuenta que a finales de los años sesenta, tanto el canal de Suez como el de Panamá no permitían aún el tránsito de los grandes mineraleros (Situación y perspectivas..., 1969, pp. 113-117). Con el trasfondo político de las ambiciones territoriales de Marruecos sobre el Sahara Occidental y el debate sobre su descolonización en el marco de la ONU, en los apartados siguientes analizaré la respuesta de los principales productores y consumidores ante esta nueva realidad, en un escenario mundial, especialmente el europeo, caracterizado por el exceso de oferta y la guerra de precios.

\section{La Société d'Études et des Participations Phosphatières (Sephos), 1968-1970}

En diciembre de 1968, las principales empresas francesas de fertilizantes, Compagnie Financière de l'Outre-Mer, PechineySt. Gobain, Établissement Kuhlmann, Pierrefitte y Société chimique de charbonnages, fundaron la Société d'Études et des Participations Phosphatières (Note sur les phosphates du Rio de Oro, 23 de septiembre de 1969). En 1969, 42\% de las acciones de la nueva empresa ya pertenecía al gobierno galo.

Por esas fechas, el Ejecutivo español aún no tenía claro cuál era la estrategia comercial que más convenía a la empresa española. En el Instituto Nacional de Industria (INI), de lo único que se era perfectamente consciente era de la necesidad de asociarse con los principales productores con el fin de minimizar riesgos. Sin embargo, los primeros contactos comerciales se establecieron con Sephos, una sociedad cuyo país de origen era el segundo consumidor mundial de fosfato y el mayor importador mundial. 
La primera reunión tuvo lugar en la presidencia del INI en Madrid el 29 de enero de 1970. A ella acudieron el presidente de Sephos, Hervé Pinet, y Julio Calleja y Alfonso Álvarez Miranda en calidad de presidentes del INI y de Fosbucraa respectivamente. Pinet explicó que la razón principal para entrar en contacto con Fosbucraa era su interés en crear "un grupo africano de productores" con objeto de salvaguardar sus intereses frente a lo que consideraban una amenaza de monopolio por parte de los productores norteamericanos. En su opinión, hasta finales de los años cincuenta, el Comptoir des Phosphates d'Afrique du Nord ${ }^{4}$ había ejercido una influencia dominante en el mercado de Europa occidental, que desapareció con su disolución tras la independencia de los países del Magreb. Esta situación, unida a la ruptura de los acuerdos con los productores norteamericanos en la segunda mitad de los años sesenta, había llevado al mercado mundial a una "gran anarquía" que se tradujo en una caída de 12 dólares en el precio internacional del fosfato en el quinquenio 1966-1970. Para evitar que la situación se deteriorara aún más, el presidente de Sephos proponía una sociedad para la comercialización del fosfato, con sede en Ginebra, y conformada por Fosbucraa, la OCP, la Compagnie Sènégalaise des Phosphates de Taïba y la Compagnie Togolaise des Mines du Benin. ${ }^{5}$

${ }^{4}$ Al finalizar la Segunda Guerra Mundial, la administración de minas de Francia, preocupada por la incidencia que podría tener en el mercado internacional la diferente calidad del fosfato extraído en Túnez y Argelia en comparación con el de Marruecos, decidió crear el Comptoir des Phosphates d'Afrique du Nord, que reunía a la OCP, a la compañía de fosfatos de Constantina (Túnez), a la Société de M’Dilla (Túnez), a la Société des Phosphates Tunisiens y a la Compagnie des Phosphates de Gafsa (Túnez). El Comptoir era un acuerdo de cártel entre diferentes empresas, que se repartían el mercado con precios y condiciones de venta comunes. El Comptoir des Phosphates d'Afrique du Nord tenía su origen en el Comptoir des Phosphates d'Algerie et de Tunisie, en el que también participaba la OCP, y que se creó en 1933.

${ }^{5}$ La Compagnie Sènégalaise des Phosphates de Taïba se creó en 1957 para explotar el yacimiento de fosfato de esa región, con una calidad de $80 \%$ TCL y unas reservas estimadas en cien millones de toneladas. Su principal accionista era Cofimer y, entre 1962 y 1965, la empresa norteamericana IMC formó parte del accionariado de la compañía. La Compagnie Togolaise des Mines du Bénin, por su parte, se creó también en 1957 y fue producto del cambio de denominación de la Société des Mines du Bénin. Creada por un grupo de empresas productoras de fosfato en Argelia y Túnez, la empresa no entró en funcionamiento hasta 1961, y explotó un yacimiento con reservas pequeñas, pero de una calidad de $80 \%$ TCL. 
Después de un periodo de tensión en las relaciones entre París y Rabat a causa de la desaparición y el asesinato de Mehdi Ben Barka en París, la vuelta a la normalidad, con la llegada de Georges Pompidou a la presidencia de la República en junio de 1969, impulsó el interés del gobierno galo y el de sus empresas de fertilizantes por recuperar el papel dominante que había tenido Francia en el mercado europeo en tiempos de la colonización, de ahí su propuesta de resucitar el antiguo comptoir con un núcleo central franco-hispano-marroquí al que se sumarían los países africanos productores de roca fosfática del área francófona. De esta manera, pretendían forzar un entendimiento con los productores estadounidenses que ayudaría a cambiar la situación de estancamiento en que se encontraba el mercado mundial de fosfatos (Nota informativa 16/70, 30 de enero de 1970).

En el INI, por el contrario, se veía a Francia como lo que era: más bien un país consumidor que uno productor. De ahí que se pensara que no tenía cabida en un futuro acuerdo entre productores como el que España deseaba cerrar con Estados Unidos y Marruecos, que sí ejercería, a juicio de Madrid, un verdadero control efectivo del mercado mundial (Comentario general a la propuesta Sephos, 26 de febrero de 1970).

Tras una reunión en la que se acordó que Pinet acudiera a Rabat con el fin de conocer las intenciones de Marruecos, las partes volvieron a reunirse en Madrid el 26 de marzo de 1970. Desde el Ministerio de Asuntos Exteriores en París se mostraban partidarios de que las empresas francesas definieran sus objetivos empresariales y adoptaran las medidas que consideraran más oportunas, siempre que no implicara compromiso alguno por parte del gobierno francés que fuera interpretado como una injerencia por algunas de las partes en conflicto en la cuestión "de la soberanía del territorio donde se encuentra el yacimiento", lo cual resulta contradictorio si tenemos en cuenta que $42 \%$ de las acciones de Sephos pertenecían al Estado galo (Note sur les phosphates du Rio de Oro, 23 de septiembre de 1969).

En el reino alauita, el presidente de Sephos se entrevistó con el gerente de la ОСР, Karim Lamrani, con el primer ministro Ahmed Laraki y con el rey Hassan II. Preocupados como 
estaban con la puesta en marcha de Fosbucraa, el gobierno marroquí era partidario del comptoir, aunque limitado en principio al "África atlántica”, y en el que querían dar entrada a Mauritania con la argucia de que en ese país se estaba investigando la existencia de fosfato en su suelo. Hervé Pinet insistía en que el "problema político" entre España y Marruecos por la soberanía del Sahara había impedido, hasta ese momento, alcanzar un acuerdo comercial sobre los fosfatos, por lo que había que aprovechar el evidente "cambio de postura" operado en los medios oficiales de Rabat, que coincidía con el clima de distensión en la relación de ambos países inaugurado ese año.

Álvarez Miranda, por el contrario, se mostró contrariado al considerar que la visita del presidente de Sephos a Marruecos había debilitado la línea inmovilista puesta en marcha por la Presidencia del Gobierno en todo lo que hacía referencia al Sahara Occidental en general, y al fosfato en particular, argumentando que daba la impresión de que España había enviado un mediador extranjero para alcanzar un acuerdo con Rabat. En el INI se sospechaba que, en el tema del fosfato, Marruecos, Argelia y Mauritania habían alcanzado un principio de acuerdo en la línea a seguir. De ahí que se negaran a firmar nada en esas condiciones. Es más, seguían convencidos de que era inviable firmar un acuerdo donde estuviera Francia (Nota informativa 46/70, 5 de junio de 1970).

Ambas partes no volvieron a reunirse hasta el 5 de junio de 1970. En el transcurso de la reunión, la representación de Sephos confirmó que las condiciones que se daban en marzo para firmar un acuerdo con Marruecos habían desaparecido tras la visita a Rabat del nuevo ministro de Asuntos Exteriores, López Bravo. Tras su negativa a tratar el asunto del Sahara, Marruecos había llegado a un acuerdo de concertación con Argelia y Mauritania con el fin de impulsar la descolonización del territorio en las Naciones Unidas (Villar, 1982; Hernando de Larramendi, 1997; Gil Pecharromán, 2008). A pesar de todo, Pinet insistía en la necesidad de llegar a un acuerdo con Marruecos para conformar un bloque productor capaz de contrarrestar a los empresarios norteamericanos.

Sin embargo, la convicción de que lo más adecuado para Fosbucraa seguía siendo un acuerdo a tres bandas entre Estados 
Unidos, Marruecos y España, llevó al Instituto a suspender las negociaciones con los franceses (Nota informativa 6/70, 5 de junio de 1970).

Días más tarde (9 de junio), el nuevo director de Siderurgia, Metalurgia y Minería del Instituto, y antiguo presidente de Fosbucraa, Alfonso Álvarez Miranda, remitió un informe al presidente del INI intitulado: "Fosfatos. Propuesta de actuación”. En ese informe, consensuado con el director general de relaciones económicas del Ministerio de Asuntos Exteriores, el señor Cerón, se insistía en la necesidad de llegar a un acuerdo comercial con los grandes productores de fosfato, además de con Túnez y Argelia. En caso de que los estadounidenses quedaran fuera, el orden de prelación sería o un acuerdo entre España y los países del Magreb o, en su defecto, un acuerdo con Marruecos. La fórmula preferida era la creación de una sociedad comercial, con sede en Suiza, que canalizaría la exportación y las ventas de sus socios. Partiendo de que la empresa norteamericana IMC deseaba nuevamente entablar conversaciones con Fosbucraa para asociarse, el informe veía con muy buenos ojos extender dicho acuerdo a los países del Magreb, especialmente a Marruecos y Túnez.

El contacto con Túnez era considerado de importancia por ser un país alejado del problema político sahariano "por razón de fronteras" y por no parecer estar contento con el comportamiento marroquí en el mercado internacional de los fosfatos. Con base en ello sería fácil hacerle concesiones técnicas o comerciales que ligaran su posición a la española en el tema de la asociación "y fisurar así en cierto modo el frente del Magreb" en lo referente a la cuestión del Sahara Occidental (Director de Siderurgia..., 9 de junio de 1970). La formación de este cártel era lo mismo que habían intentado los franceses, pero esta vez los dejaba fuera a ellos y a los países productores francófonos del África subsahariana.

Esta fórmula recibió el visto bueno del gobierno español en la reunión que se celebró en la Presidencia del Gobierno el 17 de noviembre de 1970, si bien con pequeñas modificaciones: tantear primero a Marruecos y después a las empresas de Estados Unidos, y descartar al resto de los países productores y a Francia. El contacto con Rabat se autorizaba bajo la premisa de 
que se excluía cualquier intento de participación de ocP en el capital social de Fosbucraa, que estaría bajo la vigilancia del Ministerio de Asuntos Exteriores, a través del director de relaciones económicas internacionales (Nota informativa INI 50/70, 19 de noviembre de 1970). Una vez decidida la estrategia comercial de la empresa, el siguiente en llamar a la puerta del Instituto Nacional de Industria fue la International Mineral \& Chemical Co.

\section{International Mineral \& Chemical Co. (IMC), 1971-1972}

A finales de 1970, la multinacional estadounidense IMC, propietaria de minas e industrias de fertilizantes fosfatados en Florida, volvió a ponerse en contacto con el INI. No era la primera vez que entraba en conversaciones con el gobierno español para acceder a los fosfatos del Sahara. Ya en 1966 y 1967 había habido un intento fracasado de participar en el accionariado de Enminsa (Ríos, 1989; Camprubí, 2015; Martínez, 2017a). Al igual que Sephos, su interés se centraba en la creación de una sociedad de ventas, participada al 50\% con el Instituto Nacional de Industria y con domicilio social en Lausana, París o Luxemburgo. La sociedad canalizaría las ventas de Fosbucraa y una cantidad proporcional de fosfato de la IMC.

La pretensión de este nuevo cártel no era otra que controlar el mercado mundial y conseguir un cambio en la tendencia de los precios del fosfato, "hoy envilecido por la competencia". Los norteamericanos no se planteaban una participación en el accionariado de Fosbucraa, si bien no la descartaban, siempre que las observaciones realizadas en 1966 se mantuvieran, esto es: previsiones adecuadas para que, en el caso de un eventual cambio de soberanía del territorio, los intereses de la nueva sociedad y de sus accionistas quedaran debidamente protegidos (Actualización posición IMC, 12 de noviembre de 1970; Presidente del INI a José $\mathrm{M}^{\mathrm{a}}$ López de Letona..., 29 de enero de 1971).

Todas estas condiciones se precisaron aún más en la propuesta que el 25 de febrero de 1971 presentó el presidente de la IMC, Richard A. Lenon, a Alfonso Álvarez Miranda. La sociedad por constituir tendría un capital social de un millón 
de dólares, en el que Fosbucraa tendría 51\% de las acciones y la IMC, el 49\% restante. Se repartirían el mercado en función de sus zonas naturales de comercialización: Europa y América del Sur para las exportaciones procedentes del Sahara, y Japón, Extremo Oriente y América del Norte para las de Florida. En cuanto a los precios, se establecería un nivel máximo y mínimo por calidades. En caso de que se quisiera vender por debajo del mínimo, la empresa norteamericana tendría que consultar con Fosbucraa (Richard A. Lenon a Alfonso Álvarez Miranda, 25 de febrero de 1971; Martínez, 2017b).

A espaldas del INI, el vicepresidente de la IMC, Henry Leir, ${ }^{6}$ viajó a Rabat para alcanzar un acuerdo que permitiera subir el precio de los fosfatos en el mercado mundial. En las conversaciones con Hassan II se pergeñó la idea de una posible entente comercial entre OCP, IMC y Fosbucraa. Con el beneplácito marroquí, Leir presentó el 5 de marzo una nueva oferta a los rectores del INI que modificaba por completo la anterior. Antes del 20 de abril (se quería hacer público el acuerdo antes de la visita que Hassan II realizaría a Washington dos días después), el Instituto Nacional de Industria tenía que aceptar la creación de una sociedad comercial que llevaba implícita la aceptación española de vender $50 \%$ de las acciones de Fosbucraa a la IMC (25\%) y la OCP $(25 \%)$.

A diferencia de lo que sucedió en 1967, la IMC siguió el consejo de la administración Nixon a la hora de alcanzar un acuerdo con ambas partes, ya que era la única manera de asegurar las inversiones estadounidenses. En la cuestión del Sahara Occidental, Estados Unidos mantenía una política de no injerencia ante dos aliados como España y Marruecos. No debemos olvidar que, a lo largo de los años sesenta y principios de los setenta, el volumen de la ayuda económica y financiera de Washington a Rabat fue muy importante, lo que cumplía en cierta medida una función sustitutiva de la francesa.

Si para el 31 de diciembre de 1971 no se había alcanzado ningún arreglo, quedarían sin efecto todos los acuerdos referidos a la sociedad comercial. Las prisas de la empresa norteamericana

${ }^{6}$ Henry J. Leir fue el fundador en 1939 de la empresa Ore Corporation, absorbida por la IMC en 1968, y fue también amigo personal de Ahmed Ostman, cuñado de Hassan II y exembajador de Marruecos en Washington. 
por alcanzar un convenio eran fiel reflejo de las dificultades económicas que atravesaban los principales productores. De ahí su intención de entrar en el accionariado de la empresa española en compañía de la marroquí OCP con el fin de asegurar y controlar el fosfato sahariano, lo que le permitiría negociar un acuerdo global con los demás productores estadounidenses (Alfonso Álvarez Miranda a Presidente del INI..., 6 de marzo de 1971).

Los responsables del Instituto se limitaron a tomar nota de la propuesta y no respondieron, en buena parte porque dicho acuerdo traspasaba la línea roja marcada por la Presidencia del Gobierno y también porque España iniciaría negociaciones con el país alauita, aprovechando la distensión en las relaciones entre ambos países (Hernando de Larramendi, 1997). La IMC, sin embargo, intentó alcanzar desesperadamente un acuerdo con Fosbucraa. El 5 de abril, su vicepresidente visitó el yacimiento de Bu Craa y realizó una nueva oferta que no variaba respecto a la anterior, salvo que apostaba por dar cabida a todos los productores de fosfato (Visita de Mr. Leir-Abril 71, abril de 1971).

Mientras tanto, su presidente seguía insistiendo en que la situación de la industria mundial del fosfato era preocupante y que, dado lo que denominaba "parálisis marroquí", sólo un esfuerzo común entre ambas empresas podría reactivar el mercado mundial tanto en precios como en tonelaje (Henry J. Leir a José Ma López de Letona, 29 de noviembre de 1971).

\section{L’Office Chérifien des Phosphates (OCP), 1969-1975}

Tras la caída del gobierno presidido por Abdalah Ibrahim en mayo de 1960, formado por una coalición entre nacionalistas del Istiqlal y la Unión Nacional de Fuerzas Populares, el reino cherifiano entró en un periodo de dificultades económicas que perduró hasta 1967. A la descapitalización exterior del país como consecuencia de la salida de los capitales extranjeros (franceses en su mayoría), se unieron el parón de la reforma agraria, el escaso desarrollo de la industria y el peso de un analfabetismo abrumador, que alcanzó una cifra próxima a $90 \%$ de 
la población. La muerte de Mohammed V y la llegada al trono de Hassan II en febrero de 1961 no cambiaron la situación. La contestación política y los problemas sociales que sufrió el país (descubrimiento de un complot para destronar al rey en 1963, insurrección de la población en Casablanca en 1965 y proclamación del estado de excepción, la desaparición de Ben Barka, etcétera) no eran extraños a la delicada situación económica (Vermeren, 2002).

Ante esta perspectiva, es fácil comprender que Marruecos buscara por todos los medios posibles dificultar la salida del fosfato sahariano al mercado mundial.

En las conversaciones entre el gobierno español y las empresas norteamericanas en 1966 y 1967, con el fin de crear una sociedad que permitiera la explotación de Bu Cra, Hassan II visitó Washington, pero advirtió a la administración Johnson que cualquier inversión por parte de empresas estadounidenses en el citado yacimiento sería considerada como un acto inamistoso hacia su país (Pardo, 2007). Es más, los funcionarios marroquíes de la embajada en la capital de Estados Unidos visitaron personalmente algunas de las empresas que participaban en las conversaciones, como Gulf, Texaco, Standard Oil Company of California y Grace, que formaban el llamado "grupo americano", y les avisaron que la "Saguia al Hamra era marroquí" a la vez que destacaron "el riesgo de las inversiones".

La OCP empleaba en esos momentos a 30000 asalariados, y sus ingresos suponían $25 \%$ del valor total de las exportaciones del reino cherifiano, lo que "contribuía al equilibrio presupuestario y económico del país”. La mala situación que atravesaba la empresa, unida a la fuerte competencia del fosfato norteamericano, hacían que el gobierno marroquí observara, no sin preocupación, la aparición de un nuevo competidor en el mercado mundial (Robert Danton à M. le Ministre..., 23 de febrero de 1967).

El fracaso de las conversaciones hispano-norteamericanas en 1968 produjo una sensación de alivio en las autoridades marroquíes, que nuevamente se tornó en preocupación un año más tarde (1969), cuando el gobierno español decidió financiar por sí solo la explotación del yacimiento de Bu Craa (Ríos, 1989; Camprubí, 2015; Martínez, 2017b). Las ofertas de Sephos e 
IMC a la OCP para participar en la formación de sendos cárteles fueron bien vistas por Hassan II, cuya intención era controlar la empresa española al formar parte de su accionariado, y alcanzar un acuerdo con Madrid sobre la soberanía del Sahara Occidental.

La situación económica de Marruecos cambió a partir de 1968. Con la puesta en marcha de un nuevo plan quinquenal con una voluntad clara de recuperación, Hassan II entendió que era el Estado el que, a través de la inversión pública, tenía que tomar la iniciativa. Los principales objetivos del programa fueron tres: desarrollar una agricultura orientada hacia la exportación gracias a la construcción de embalses y la extensión de la superficie de regadío; la creación de una industria química basada en la exportación de fosfatos y, por último, la atracción de capitales extranjeros para el desarrollo del turismo (Ganiage, 1994).

Ante las nuevas perspectivas económicas que se abrían para el país y el interés del gobierno español por llegar a un acuerdo comercial con la OCP, y aprovechando la distensión en las relaciones entre ambos países que se había iniciado en 1970, Rabat puso de nuevo sobre la mesa las reclamaciones sobre el Sahara Occidental. La primera reunión tuvo lugar en París el 22 de febrero de 1971. En el transcurso de la misma, la parte marroquí se mostró partidaria de firmar un acuerdo comercial, siempre que se alcanzaran acuerdos políticos relacionados con la soberanía de la colonia española. En las dos conversaciones siguientes, que tuvieron lugar a finales de marzo y principios de abril, el gerente de la OCP, Karim Lamrani, siguió empeñado en un acuerdo global que implicara la entrada de su empresa en el accionariado de Fosbucraa y en la creación de una sociedad comercial, pero ligando el acuerdo a un convenio al más alto nivel que incluyera el traspaso de soberanía del Sahara a Marruecos (El presidente del INI..., 26 de febrero de 1971; Claudio Boada a López de Letona, 1 de abril de 1971).

A pesar de la advertencia española de que si no llegaban a un acuerdo comercial sobre cuotas de mercado y precios, lo harían con la IMC, las conversaciones quedaron en punto muerto. Tres meses más tarde (6 de julio) hubo una entrevista secreta al más alto nivel con los representantes marroquíes en el Mi- 
nisterio de Industria. Por la parte española asistieron el ministro de Industria, López de Letona, y Álvarez Miranda, y por la parte marroquí, Karim Lamrani y el embajador de su país en Madrid. López de Letona insistió en eliminar cualquier aspecto político de la conversación y limitarse a buscar un pacto de colaboración comercial e industrial relacionado con la venta de fosfatos y la fabricación de ácido fosfórico. La parte marroquí se mostró de acuerdo, siempre que se permitiera a su país participar con $50 \%$ en la explotación de las riquezas mineras del Sahara y en su comercialización. Como ambas posturas permanecieron inamovibles, las partes acordaron redactar una nota en el plazo de dos semanas y remitirla a sus respectivos gobiernos para fijar una posición definitiva (Alfonso Álvarez de Miranda a Presidente del INI..., 7 de julio de 1971).

Dos días después, Marruecos remitió un memorándum al INI en el que reafirmaba sus pretensiones: participación accionarial en Fosbucraa y en todas las riquezas mineras del Sahara, y creación de sociedades mixtas hispano-marroquíes. La respuesta española se demoró hasta el 20 de octubre, pero Madrid se mantuvo fiel a su posición: creación de una sociedad comercial y colaboración industrial (Memorándum, 8 de julio de 1971).

En 1972, la situación del mercado internacional de fosfatos cambió. Una serie de malas cosechas en Estados Unidos, acompañada por algunas sequías que asolaron China y la URSS, provocaron un aumento en la demanda de cereales que disparó la solicitud de fertilizantes y de mineral de roca fosfática, lo que dio lugar a un cambio en la tendencia de los precios. El fosfato de Florida de calidad media se encareció en dos dólares por tonelada y el marroquí, entre un dólar y dólar y medio (Oualalou, 1975; Martínez, 2017b; Stowasser, 1976). En esta nueva coyuntura, y teniendo en cuenta la negativa española de abrir el accionariado de Fosbucraa a la participación marroquí y a cualquier posible negociación sobre el Sahara Occidental, la ocP cambió de estrategia y aceptó pactar con Fosbucraa cuotas de mercado y precios a partir de la formación de un cártel.

Cuando se reanudaron las conversaciones en la primavera de ese año, ambas empresas pusieron sobre la mesa sus respectivos planes de producción para el quinquenio 1972-1976. Fosbucraa aspiraba a alcanzar seis millones de toneladas en 1976 y 
la OCP, dieciocho millones de toneladas. Los responsables marroquíes pusieron reparos a la cantidad que Fosbucraa tenía previsto vender en 1976 por temor a generar una situación de exceso de oferta en el mercado europeo, teniendo en cuenta las cantidades importadas de Florida. Si se considera que más de $80 \%$ de las futuras ventas de la OCP iban destinadas al mercado europeo, se entienden las prevenciones marroquíes respecto a Fosbucraa.

Ambas empresas llegaron a un acuerdo para establecer una política común de precios y cantidades para Italia, Francia Alemania y Rumanía, y la OCP se reservó el mercado británico, Benelux y Yugoeslavia. Respecto al mercado español, se alcanzó un acuerdo verbal sobre precios y toneladas para 1973 y 1974. Fosbucraa se encargaría de abastecer el mercado español con 500000 toneladas en 1973 y 750000 en 1974, mientras que el resto, hasta completar una cifra próxima a los dos millones, correría a cargo de la ocp. No obstante, Karim Lamrani mostró inquietud por la posible reacción de los productores norteamericanos, al tiempo que aprovechó la ocasión para recordar a sus homólogos españoles la necesidad de buscar una solución al tema del Sahara Occidental que cumpliera con las pretensiones del reino alauita y Mauritania (Claudio Boada a López de Letona, 20 de marzo de 1972; Alfonso Álvarez Miranda a José M ${ }^{a}$ López de Letona, 12 de abril de 1972; Alfonso Álvarez Miranda a Claudio Boada, 29 de abril de 1972; Nota informativa 36/72, 26 de mayo de 1972; Martínez, 2017b).

La reacción de los clientes españoles de la OCP no se hizo esperar y amenazaron éstos con aumentar sus compras a Estados Unidos si los precios del fosfato subían en 1973. De igual modo, los productores de Florida reaccionaron poniendo en marcha una política agresiva en el mercado español: ofrecieron rebajas de precios de entre dos y tres dólares la tonelada por debajo del precio de referencia (cuadro 1).

Esto derivó en una reunión de urgencia en Madrid entre los directores generales de Fosbucraa y la OCP en la que se acordó intentar a corto plazo limitar la oferta estadounidense en el mercado español a no más de 50000 toneladas anuales e ir sustituyéndola paulatinamente por la oferta hispano-marroquí (Alfonso Álvarez Miranda a presidente del INI, 3 de octubre 
Cunadro 1. Precios Fob de referencia en el mercado español, 1972 (dólares por Tm)

\begin{tabular}{lcc}
\hline Productor & $\begin{array}{c}\text { Calidad } \\
\text { (TCL) }\end{array}$ & Precio \\
\hline Estados Unidos (Florida) & $75 / 74$ & 11.18 \\
Estados Unidos (Florida) & $73 / 72$ & 10.30 \\
Union Phosphatière Africaine (UPHA) & $80 / 82$ & 13.25 \\
Office Chérifien des Phosphates (OCP) & $75 / 73$ & 11.75 \\
\hline
\end{tabular}

Fuente: Problemas del mercado español en 1973, 3 de octubre de 1972.

de 1972). Sin embargo, 1973 fue el año que marcó el inicio del boom fosfatero que duró hasta 1976. A raíz de la fuerte subida del precio del petróleo y la creciente demanda de abonos fosfatados con la entrada de nuevos consumidores (Brasil y China), el precio del fosfato se disparó. En un entorno de grandes subidas de precios, ambas empresas volvieron a reunirse en Madrid el 26 de abril de 1973.

La sorpresa para los representantes españoles fue la constatación del acercamiento que se había producido entre la OCP y la Phosphate Rock Export Association, sociedad creada a principios de 1972 y que agrupaba a los principales exportadores de fosfato de Estados Unidos. Karim Lamrani reconoció, además, que habían llegado a un acuerdo con los estadounidenses para establecer un "Instituto Mundial del Fosfato" en Rabat, en el que, según Lamrani, los norteamericanos se habían mostrado contrarios a la entrada de España. Por iniciativa de la OCP y la IMC, el 21 de junio de 1973 se creó en Rabat el Instituto Internacional del Fosfato. Además de estas dos empresas, entre los miembros fundadores figuraban empresas de Senegal (Taiba), Togo (Benin), Túnez (Gafsa), Argelia (Recherches et Exploitations Minières), Jordania (Jordan Phosphate), Siria (Société Gèneral des Phosphates), Reino Unido (British Phosphate) y Brasil (Quimbrasil, S.A.). El caso de Argelia y Brasil eran intereses de la OCP. La presencia de la empresa British Phosphate Commisioners estaba motivada porque controlaba la explotación y la comercialización del fosfato de Oceanía (Islas Christ- 
mas y Ocean Maru), que abastecía casi en exclusiva el mercado de Australia. Con un consejo directivo controlado por la OCP y la IMC, los objetivos del Instituto se centraban en promover la producción de fosfato y en mantener contacto entre ellos y con los organismos mundiales competentes (Nota informativa 66/73, 15 de julio de 1973). En realidad, la OCP y Phosrock buscaban recuperar su dominio en el mercado europeo y mundial, intentando lastrar el crecimiento industrial de Fosbucraa. La reacción de la empresa española fue iniciar un acercamiento con Phosrock sin por ello romper relaciones con la OCP (Alfonso Álvarez Miranda a presidente del INI, 27 de abril de 1973).

En el otoño de 1973, la ОсP desencadenó una subida de precios que fue seguida por los productores de roca fosfática (Anani Mensah, 2003; Zenaidi Karray, 1987; Martínez, 2017b). De inmediato, las industrias de fertilizantes españolas comunicaron tanto a Fosbucraa como al gobierno español su intención de repercutir estas subidas en el precio de sus productos. Desde el INI se buscó la manera de que el alza de precios de los abonos destinados al campo español tuviera el menor impacto posible, sin poner en peligro (eso pensaban ellos) el desarrollo de Fosbucraa.

En la reunión mantenida con la OCP en París el 22 de noviembre de 1973, y en contra de los deseos del consejo de administración de Fosbucraa, los responsables españoles plantearon a sus homólogos marroquíes la necesidad de reducir su aportación al mercado español en favor de las importaciones procedentes del Sahara. Los representantes del INI argumentaron las ventajas que tendría para la ocP que esa cantidad de fosfato de alta calidad no compitiera con ellos en el mercado europeo. Al final se llegó a un acuerdo y se firmó un nuevo reparto para el mercado español. Las importaciones españolas de fosfato cayeron a la mitad entre 1973 y 1975, de dos millones a un millón de toneladas. La amenaza de las empresas españolas de fertilizantes fosfatados tuvo su recompensa: en un contexto mundial inflacionista lograron aumentar su cuota de fosfato procedente del Sahara a un precio inferior al del mercado (Claudio Boada a ministro de Industria, 26 de noviembre de 1973). La gran perjudicada fue Fosbucraa, que perdió la mayor parte de sus clientes en el exterior. 
La caída de la demanda en 1975 y la ruptura de los acuerdos entre los principales productores provocaron una vuelta al escenario de 1971, lo cual, sumado a la salida española del Sahara y el escenario de guerra que se dio entre Marruecos y el Frente Polisario, determinaron una situación de parálisis y de futuro incierto de Fosbucraa que marcó el devenir del fosfato sahariano a corto y a medio plazos.

\section{Conclusiones}

En una coyuntura mundial marcada por la escasa demanda de fosfato natural, por la caída de la cotización internacional del mineral de roca fosfática y por la guerra de precios entre los principales productores, entró en escena un nuevo productor, Fosbucraa, que introducía más inestabilidad a un mercado de por sí ya inestable. En ese contexto, los mayores productores $\mathrm{y}$ algún consumidor intentaron controlar el acceso al mercado del fosfato sahariano con estrategias empresariales que buscaban también dar satisfacción a las ambiciones territoriales del reino alauita sobre el Sahara Occidental.

Una vez perdido su imperio africano, las industrias de fertilizantes francesas y el gobierno francés intentaron, a través de Sephos, recuperar el timón del mercado mundial de fosfatos mediante la creación de un cártel euroafricano que obligara a los productores norteamericanos a llegar a acuerdos sobre cuotas de mercado y precios, para volver así a la senda de principios de los años sesenta. De ahí las presiones sobre el gobierno español para superar las discrepancias políticas con Rabat y llegar a un acuerdo satisfactorio para todos.

La estadounidense IMC intentó lo mismo, con la diferencia de que su estrategia le llevó a un acuerdo con la marroquí OCP para adquirir la mitad de las acciones de la empresa española. La negativa del gobierno español a cualquier participación extranjera, especialmente de la OCP, en el accionariado de Fosbucraa, y el deseo de llegar a convenios exclusivamente comerciales con la empresa marroquí, y en menor medida con la IMC, obligó a Rabat a adoptar varias estrategias que combinaran su deseo de limitar el acceso del fosfato sahariano al mercado 
mundial con sus reclamaciones territoriales sobre el Sahara Occidental.

Entre 1966 y 1971, la OCP apostó por la estrategia política de reivindicación del territorio sahariano sobre lo demás. Cuando cambió la coyuntura del mercado en 1972, y ante la negativa española a ceder territorio en el Sahara o a cualquier participación marroquí en sus riquezas mineras, la OCP cambió de táctica y formó un cártel con la empresa española con el único fin de controlar la cuota de mercado y los precios del fosfato sahariano en Europa. La estrategia inicial del gobierno español de alcanzar acuerdos comerciales con las dos mayores empresas exportadoras mundiales de fosfato, y tener de esa manera acceso al mercado mundial, fracasó desde el momento en que, al verse presionado por las empresas de fertilizantes españolas, priorizó, en contra de la opinión del propio consejo de administración de la empresa, el mercado nacional en detrimento del resto, lo que llevó a Fosbucraa a la pérdida de clientes en Europa y Asia.

Dirección institucional del autor:

Universidad de las Palmas de Gran Canaria

Juan de Quesada, 30

Las Palmas de Gran Canaria

35001, España

\section{Referencias}

Anani Mensah, A. (2003). Dynamique et comportements stratégiques sur le marché international du phosphate. Mondes en Développement, 122(2), 37-56. http://dx.doi.org/10.3917/med.122. 0037

Bureau of Mines (s.a.). Minerals yearbook metals and minerals (except fuels), 1960-1970. Recuperado de https://minerals.usgs.gov/minerals/pubs/usbmmyb.html

CAmprubí, L. (2015). Resource geopolitics: Cold war technologies, global fertilizers, and the fate of Western Sahara. Technology and Culture, 56(3), 676-703. http://dx.doi.org/10.1353/tech.2015. 0077

Díaz Morlán, P. (2015). Empresarios, militares y políticos. La Com- 
pañia Española de Minas del Rif(1907-1967). Madrid: Marcial Pons Historia. https://doi.org/10.1016/j.ihe.2016.07.005

Ganiage, J. (1994). Histoire contemporaine du Maghreb de 1830 à nos jours. París: Fayard.

Gil Pecharromán, J. (2008). La política exterior del franquismo (1939. 1975). Entre Hendaya y El Aiún. Barcelona: Flor del Viento.

Hernando de LARRAmendi, M. (1997). La política exterior de Marruecos. Madrid: Mapfre.

Madariaga, M. R. de (1999). España y el Rif. Crónica de una historia casi olvidada. Melilla: Ciudad Autónoma de Melilla.

Martínez Milán, J. M. (2017a). La larga puesta en escena de los fosfatos del Sahara Occidental, 1947-1969. Revista de Historia Industrial, 26(69), 177-205. Recuperado de https://www.raco. cat/index.php/HistoriaIndustrial/article/view/335602

Martínez Milán, J. M. (2017b). Empresa pública y minería en el Sahara Occidental: Fosfatos de Bu Craa, S.A., 1969-1983. Boletín Geológico y Minero, 128(4), 913-929. Recuperado de http://www. igme.es/boletin/2017/128_4/BGM_128_4_Art-3.pdf

Morales Lezcano, V. (1976). El colonialismo hispano-francés en Marruecos (1898-1927). Madrid: Siglo XXI.

Oualalou, F. (1975). La politique phosphatière Marocaine et les tentatives d'adaptation aux variations de la demande internationale. Annuaire de l'A frique du Nord, (13), 41-70. Recuperado de http://aan.mmsh.univ-aix.fr/Pdf/AAN-1974-13_34.pdf

Pardo SAnz, R. (2007). El proceso de descolonización. En M. Oreja y R. Sánchez (Eds.), Entre la bistoria y la memoria. Fernando María Castiella y la política exterior de España, 1957-1969 (pp. 83-134). Madrid: Real Academia de Ciencias Morales y Políticas.

Ríos, J. M. (1989). „iSahara!! iiSahara!! La aventura de los fosfatos, un episodio inédito. Madrid: Fundación Gómez Pardo.

StowAsser, W. F. (1976). The mineral industry of Morocco. En Bureau of Mines, Minerals yearbook area reports. International 1973, 3, pp. 623-632. Recuperado de: http://images.library. wisc.edu/EcoNatRes/EFacs2/MineralsYearBk/MinYB1973v3/ reference/econatres.minyb1973v3.wstowasser.pdf

Vermeren, P. (2002). Histoire du Maroc depuis l'indépendance. París: La Découverte.

VILlaR, F. (1982). El proceso de autodeterminación del Sahara. Valencia: Fernando Torres.

Zenaidi KARRAy, B. (1987). Le Marché mondial des phosphates et des engrais phosphatés. París: Economica. 


\section{Material de archivo}

Actualización posición IMC, Madrid, 12 de noviembre de 1970. Archivo de la Sociedad Estatal de Participaciones Industriales, Fosbucraa, caja 44, doc. 3, reservado.

Alfonso Álvarez de Miranda a Presidente del INI. Fosfatos-Conversaciones Karim Lamrani, Madrid, 7 de julio de 1971. Archivo de la Sociedad Estatal de Participaciones Industriales, Fosbucraa, caja 44, doc. 4, reservado.

Alfonso Álvarez Miranda a Claudio Boada, Madrid, 29 de abril de 1972. Archivo de la Sociedad Estatal de Participaciones Industriales, Fosbucraa, caja 44, doc. 4.

Alfonso Álvarez Miranda a José M ${ }^{a}$ López de Letona, Madrid, 12 de abril de 1972. Archivo de la Sociedad Estatal de Participaciones Industriales, Fosbucraa, caja 44, doc. 4.

Alfonso Álvarez Miranda a Presidente del INI, Madrid, 27 de abril de 1973. Archivo de la Sociedad Estatal de Participaciones Industriales, Fosbucraa, caja 44, doc. 4.

Alfonso Álvarez Miranda a Presidente del INI, Madrid, 3 de octubre de 1972. Archivo de la Sociedad Estatal de Participaciones Industriales, Fosbucraa, caja 44, doc. 4.

Alfonso Álvarez Miranda a Presidente del INI. Relaciones con IMC febrero-marzo 1971, Madrid, 6 de marzo de 1971. Archivo de la Sociedad Estatal de Participaciones Industriales, Fosbucraa, caja 44 , doc. 3 , reservado.

Claudio Boada a López de Letona, Madrid, 1 de abril de 1971. Archivo de la Sociedad Estatal de Participaciones Industriales, Fosbucraa, caja 44, doc. 4.

Claudio Boada a López de Letona, Madrid, 20 de marzo de 1972. Archivo de la Sociedad Estatal de Participaciones Industriales, Fosbucraa, caja 44, doc. 4.

Claudio Boada a Ministro de Industria, Madrid, 26 de noviembre de 1973. Archivo de la Sociedad Estatal de Participaciones Industriales, Fosbucraa, caja 44, doc. 4.

Comentario general a la propuesta Sephos, Madrid, 26 de febrero de 1970. Archivo de la Sociedad Estatal de Participaciones Industriales, Fosbucraa, caja 44, exp. E.VI22, doc. 3.

Director de Siderurgia, Metalurgia y Minería a Presidente del INI. Fosbucraa. Propuesta de actuación (II), Madrid, 9 de junio de 1970. Archivo de la Sociedad Estatal de Participaciones Industriales, Fosbucraa, caja 45, doc. 2.

El presidente del INI (Claudio Boada) al ministro de Industria 
(López de Letona), Madrid, 26 de febrero de 1971. Archivo de la Sociedad Estatal de Participaciones Industriales, Fosbucraa, caja 44 , doc. 4.

Henry J. Leir a José Ma López de Letona, Luxemburgo, 29 de noviembre de 1971. Archivo de la Sociedad Estatal de Participaciones Industriales, Fosbucraa, caja 44, doc. 3.

Memorándum, Rabat, 8 julio de 1971. Archivo de la Sociedad Estatal de Participaciones Industriales, Fosbucraa, caja 44, doc. 4.

Nota informativa 16/70, Conversación con Sephos, Madrid, 30 de enero de 1970. Archivo de la Sociedad Estatal de Participaciones Industriales, Fosbucraa, caja 44, exp. E.VI22, doc. 3, reservado. Nota informativa 36/72. Informe visita a Rabat, Madrid, 26 de mayo de 1972. Archivo de la Sociedad Estatal de Participaciones Industriales, Fosbucraa, caja 44, doc. 4.

Nota informativa 46/70. Tercera conversación con Sephos, Madrid, 5 de junio de 1970. Archivo de la Sociedad Estatal de Participaciones Industriales, Fosbucraa, caja 44, exp. E.VI22, doc. 3.

Nota informativa 6/70, Cuarta conversación con Sephos, Madrid, 5 de junio de 1970. Archivo de la Sociedad Estatal de Participaciones Industriales, Fosbucraa, caja 44, exp. E.VI22, doc. 3.

Nota informativa 66/73, Madrid, 15 de julio de 1973. Archivo de la Sociedad Estatal de Participaciones Industriales, Fosbucraa, caja 44, doc. 4.

Nota informativa INI 50/70, Madrid, 19 de noviembre de 1970. Archivo de la Sociedad Estatal de Participaciones Industriales, Fosbucraa, caja 45, doc. 9, reservado.

Note sur les phosphates du Rio de Oro, París, 23 de septiembre de 1969. Centre des Archives Diplomatiques de Nantes, Fond Rabat Ambassade 1956-1989, Ministère des Affaires Étrangères, Direction des Affaires Économiques et Financières.

Presidente del INI a José $\mathrm{M}^{\text {a }}$ López de Letona (ministro de Industria), Madrid, 29 de enero de 1971. Archivo de la Sociedad Estatal de Participaciones Industriales, Fosbucraa, caja 44, doc. 3, confidencial y reservado.

Problemas del mercado español en 1973, Madrid, 3 de octubre de 1972. Archivo de la Sociedad Estatal de Participaciones Industriales, Fosbucraa, caja 44, doc. 4.

Resumen Anual de Trabajos, 1968. Archivo de la Sociedad Estatal de Participaciones Industriales, Empresa Nacional Minera del Sahara, S.A., caja 4493, doc. 12.

Resumen anual de trabajos, Madrid, 1970. Archivo de la Sociedad Estatal de Participaciones Industriales, Fosbucraa, caja 4904. 
Richard A. Lenon a Alfonso Álvarez Miranda, s.1., 25 de febrero de 1971. Archivo de la Sociedad Estatal de Participaciones Industriales, Fosbucraa, caja 44, doc. 3.

Robert Danton à M. le Ministre de l'Économie et des Finances, $\mathrm{n}^{\circ}$ 772. Exploitation des phosphates d'El Ayoun dans la Sakiet el Hamra, Rabat, 23 de febrero de 1967. Centre des Archives Diplomatiques de Nantes, Fond Rabat Ambassade 1956-1989, Ministère des Affaires Étrangères, Direction des Affaires Économiques et Financières.

Situación y perspectivas del mercado mundial de fosfatos, Madrid, 1969. Archivo de la Sociedad Estatal de Participaciones Industriales, Fosbucraa, caja 4514.

Visita de Mr. Leir-Abril 71, Madrid, abril de 1971. Archivo de la Sociedad Estatal de Participaciones Industriales, Fosbucraa, caja 44, doc. 3 , reservado.

Yacimiento de fosfato de Bu Craa. Centro de Documentación del Instituto Geológico y Minero de España, fondo Sahara, Dirección General de Plazas y Provincias Africanas, núm. registro 02291. 